\title{
Direct Cleavage, Proteasomal Degradation and Sequestration: Three Mechanisms of Viral Subversion of Type I Interferon Responses
}

\author{
Gerald M. Mclnerney Gunilla B. Karlsson Hedestam \\ Department of Microbiology, Tumor and Cell Biology, Karolinska Institutet, Stockholm, and Swedish Institute for \\ Infectious Disease Control, Solna, Sweden
}

\section{Key Words}

Innate immunity $\cdot$ Infection $\cdot$ Interferon- $\alpha / \beta \cdot$ Virus

\begin{abstract}
The host type I interferon (IFN) system is central in antiviral defence and represents one of the greatest obstacles for a virus to overcome in order to establish a productive infection. Viruses have evolved many different mechanisms to repress the effects of the type I IFN system. For example, a number of viruses encode viral proteases, which can directly cleave and inactivate key components of the type I IFN induction and signalling pathway. Others recruit the ubiquitin proteasome system to destabilise proteins that are important for IFN responses. There are also many known viral proteins, which bind to and sequester proteins of the type I IFN system in an inactive state. Here, we review each of these different mechanisms of viral escape from the type I IFN response with examples from a range of viruses.
\end{abstract}

Copyright $\odot 2009$ S. Karger AG, Basel

\section{Introduction}

Intact innate immune responses are critical for the early defence against virus infection with type I interferons (type I IFNs, IFN- $\alpha / \beta$ ) playing one of the most important roles. Type I IFNs are potent anti-viral cytokines

\section{KARGER}

Fax +41613061234 E-Mail karger@karger.ch www.karger.com (c) 2009 S. Karger AG, Basel

1662-811X/09/0016-0599\$26.00/0

Accessible online at:

www.karger.com/jin to which almost all cell types are responsive. In the absence of a functional type I IFN response, sensitivity to some virus infections is increased, as shown both in mice rendered genetically defective for genes in the type I IFN response pathway [1-3] and in humans who harbour natural mutations in the type I IFN signalling pathway [4]. A virus that causes an asymptomatic infection in a healthy host often induces severe disease in a host lacking a functional type I IFN response [4-6].

The central role of type I IFN responses in broad antiviral defences is also illustrated by the extraordinary range of viral antagonists that target this system. In fact, there are known examples of virus-encoded antagonists that interfere with almost every step of the type I IFN induction and signalling pathways identified until now [7]. Clearly, different viruses have evolved distinct mechanisms to interfere with the type I IFN response in order to suit their own needs to replicate and persist in the host and target population. The diversity of type I IFN antagonists and cellular targets were recently reviewed [7-9]. In the current article, we focus on the mechanisms of action of different classes of type I IFN antagonists. Specifically, we describe virus-encoded proteases that directly cleave cellular targets in the type I IFN pathway, viral gene products that mediate recruitment of the ubiquitin proteasome system (UPS) for degradation of cellular targets, and virus-encoded proteins that lead to sequestration and inactivation of host proteins involved in

Dr. Gerald M. McInerney

Department of Microbiology, Tumor and Cell Biology

Karolinska Institutet

Box 280, SE-171 77 Stockholm (Sweden)

Tel. +46 8457 2697, Fax +468337 272, E-Mail gerald.mcinerney@ki.se 
Table 1. Mechanisms of viral subversion of type I IFN responses

\begin{tabular}{|c|c|c|c|c|}
\hline Virus & Antagonist & Target & Effect & Ref. \\
\hline \multicolumn{5}{|l|}{ Direct cleavage by viral proteases } \\
\hline Hepatitis A virus & $3 \mathrm{C}^{\text {pro }} 3 \mathrm{ABC}$ & MAVS & blocks IFN induction & 36 \\
\hline Hepatitis $\mathrm{C}$ virus & $\mathrm{NS} 3 / 4 \mathrm{~A}$ & TRIF, MAVS & blocks IFN induction & $15,34,35$ \\
\hline Poliovirus & $3 \mathrm{C}^{\text {pro }}$ & NF-кB p65 & inhibits IFN induction & 31 \\
\hline \multicolumn{5}{|l|}{ Recruitment of UPS } \\
\hline Bovine Herpes virus & bICP0 & IRF-3 & blocks IFN induction & 40 \\
\hline Bovine viral diarrhea virus & $\mathrm{N}^{\text {pro }}$ & IRF-3 & blocks IFN induction & 43 \\
\hline Classical swine fever virus & $\mathrm{N}^{\text {pro }}$ & IRF-3 & blocks IFN induction & 42 \\
\hline Human immunodeficiency virus 1 & Vif & APOBEC3G & blocks IFN effector protein & 49 \\
\hline Human parainfluenza virus 2 & $\mathrm{~V}$ & STAT2 & blocks IFN signalling & 45 \\
\hline Influenza A virus & NS1 & TRIM25 & blocks IFN induction & 61 \\
\hline Mumps virus & $\mathrm{V}$ & STAT1 & blocks IFN signalling & 46 \\
\hline Respiratory syncytial virus & NS proteins & STAT2 & blocks IFN signalling & 62 \\
\hline Rotavirus & Nsp1 & IRF-3 & blocks IFN induction & 41 \\
\hline Simian virus 5 & $\mathrm{~V}^{1}$ & STAT1 & blocks IFN signalling & 44 \\
\hline \multicolumn{5}{|c|}{ Sequestration of key components of IFN system } \\
\hline African swine fever virus & A238L & $\mathrm{NF}-\kappa \mathrm{B}$ & blocks IFN induction & 58 \\
\hline Cytomegalovirus & IE1 & STAT1/STAT2 & blocks IFN signalling & 63 \\
\hline Hepatitis $\mathrm{C}$ virus & Core & STAT1 & blocks IFN signalling & 64 \\
\hline Hepatitis B virus & Polymerase & STAT1 & blocks IFN signalling & 65 \\
\hline Human papilloma virus 18 & E6 & Tyk2 & blocks IFN signalling & 59 \\
\hline Hendra, Nipah viruses & $\mathrm{V}$ & STAT1/STAT2 & blocks IFN signalling & 66 \\
\hline Influenza $\mathrm{A}$ virus & NS1 & RIG-I/MDA5 & blocks IFN induction & 52 \\
\hline Rinderpest virus & $\mathrm{V}$ (also $\mathrm{P}$ and $\mathrm{C}$ ) & STAT1 & blocks IFN signalling & 67 \\
\hline Vaccinia virus & $\mathrm{B} 18 \mathrm{R}$ & IFN $-\alpha / \beta$ & blocks IFN signalling & 60 \\
\hline Vaccinia virus & E3L & RIG-I/MDA5 & blocks IFN induction & 51 \\
\hline Vaccinia virus & $\mathrm{H} 1$ & STAT1/STAT2 & blocks IFN signalling & 68 \\
\hline Vaccinia virus & $\mathrm{K} 3 \mathrm{~L}$ & PKR & blocks IFN effector protein & 57 \\
\hline
\end{tabular}

the type I IFN response (table 1). For space considerations, we limit this review to selected examples and we do not discuss viral antagonists for which the mechanism of action remains unknown, for example the Semliki Forest virus nsp2 protein [10].

\section{Type I IFN Induction and Signalling}

The IFN system is evolutionarily well conserved and most animal cells have the capacity to produce type I IFNs in response to virus infection and to amplify the response via autocrine as well as paracrine signalling through the type I IFN receptor (IFNAR; fig. 1). Signalling allows uninfected cells to establish a potent anti-viral state, which renders them capable of aborting viral replication should they encounter a virus. The induction of type I IFNs is mediated by the detection of incoming RNA genomes or viral replication intermediates by cytosolic and endosomal receptors. The main 2 cytosolic re- ceptors responsible for viral RNA recognition are retinoic acid-inducible gene-I (RIG-I) and melanoma differentiation-associated gene 5(MDA5) [11, 12], which appear to play complementary roles in virus recognition [13]. RIG-I and MDA5 signal through the mitochondrial adaptor protein MAVS (IPS-1/VISA/Cardif) [14-17], which recruits and activates IFN regulatory factor 3 (IRF3 ) and nuclear factor- $\kappa \mathrm{B}(\mathrm{NF}-\kappa \mathrm{B})$, a p65/p50 heterodimer. Both IRF-3 and NF- $\kappa$ B are targets for viral interference as discussed below. IRF-3 is a constitutively expressed cytosolic protein, which upon phosphorylation by TBK1 and IKK $\varepsilon$ [18] dimerizes and translocates to the nucleus. Activation and nuclear translocation of NF- $\kappa \mathrm{B}$ requires polyubiquitination and proteasomal degradation of the cytoplasmic inhibitor IкB [19]. Once a tripartite complex consisting of activated IRF-3, NF- $\kappa \mathrm{B}$ and ATF/c-Jun docks on the IFN promoter, the primary type I IFN subsets, IFN- $\beta$ and IFN- $\alpha 4$, are expressed [20]. 


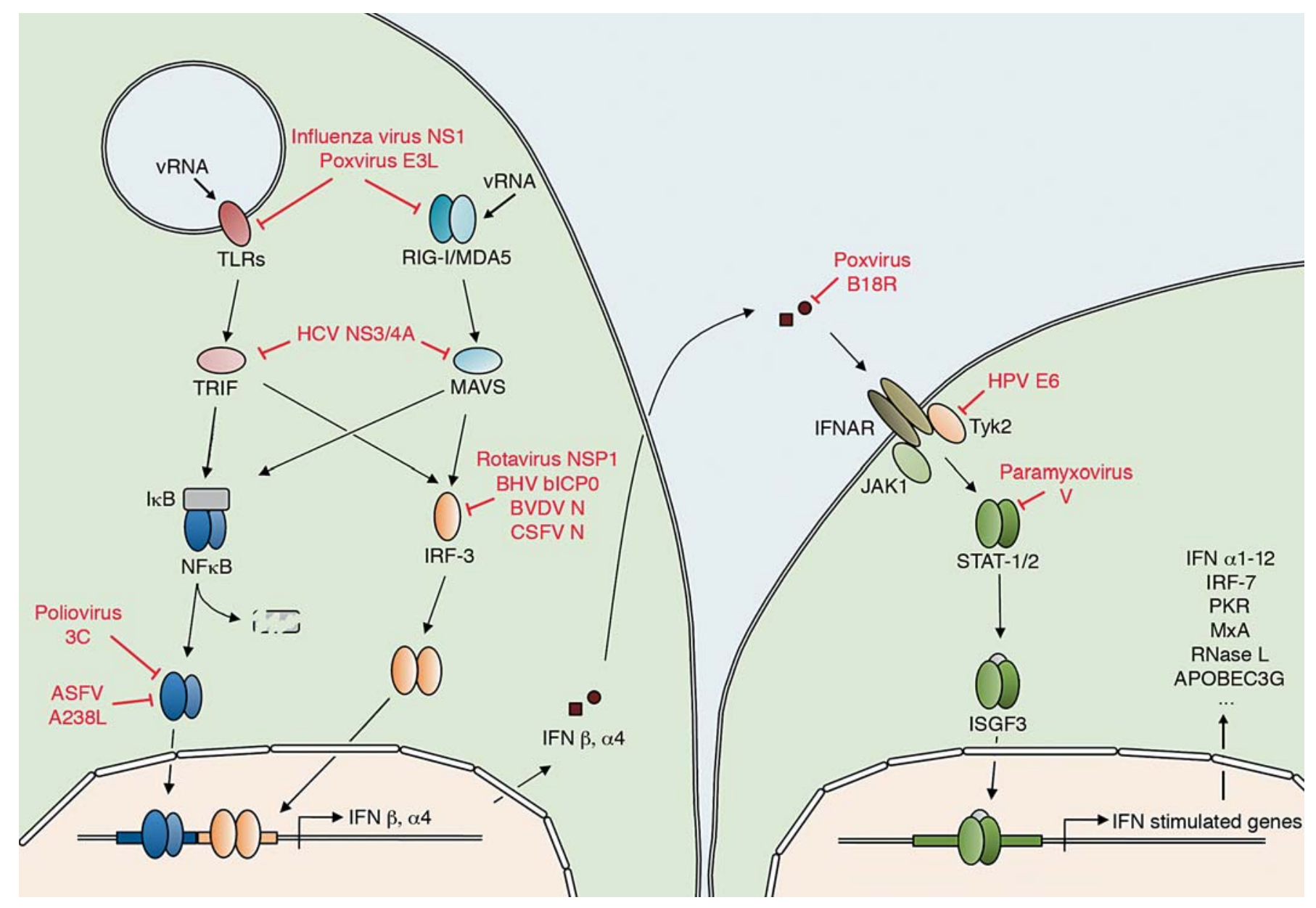

Fig. 1. The IFN induction and signalling pathways. The presence of viral RNAs in infected cells activates the cytosolic receptors RIG-I and MDA5 and a subset of TLRs in endosomal compartments. Activation of RIG-I/MDA5 and TLR3 leads to activation of NF- $\kappa \mathrm{B}$ and IRF-3 via the MAVS and TRIF intermediates, respectively. The activated transcription factors relocate to the nucleus where they promote the expression of the early type I IFN subsets, IFN- $\beta$ and IFN- $\alpha 4$. These molecules are secreted and act in autocrine and paracrine fashion to stimulate the IFNAR. Once the IFNAR becomes ligated, the coordinated action of its associated kinases JAK1 and Tyk2 leads to assembly and activation of heterodimers of STAT1 and STAT2. These form higher-order complexes known as ISGF3 with other cellular proteins, translocate to the nucleus and activate transcription of later IFN subsets and a range of IFN-stimulated genes, including PKR, RNase L and APOBEC3G. Mechanisms of viral antagonism exist at every step of this pathway, some of which are indicated in red. For details, see text.
All cell types have the machinery for type I IFN production through the cytosolic receptors, RIG-I and MDA5 [21]. In addition, selected cell types express Tolllike receptors (TLR) capable of detecting viral genomes in endosomal compartments as reported for TLR3, TLR7/8 and TLR9 [22-25]. TLR7/8 and TLR9, which signal via the MyD88 adaptor molecule, mediate type I IFN production by plasmacytoid dendritic cells, which are highly specialized and capable of extremely high levels of IFN- $\alpha$ production, likely due to their constitutive expression of IRF-7 [26]. IRF-7 was termed the master regulator of type I IFN responses, as mice lacking IRF-7 have a more severe defect in type I IFN production than mice lacking either IRF-3 or MyD88 [1]. The TLR and RIG-I/ MDA5 signalling pathways are extensively reviewed [27]. Here, we only highlight that MAVS is an adaptor protein for RIG-I/MDA5 and TRIF is an adaptor protein for TLR3. Both these adaptors are targets for viral interference as discussed below.

Secretion of the primary IFNs and their subsequent engagement of the ubiquitously expressed IFNAR stimulates JAK1- and Tyk2-mediated phosphorylation of the 
latent signal transducers and activators of transcription (STATs) 1 and 2, leading to their heterodimerization. Subsequent interactions between STAT1/2 heterodimers and cytoplasmic IRF-9 form IFN-stimulated gene factor 3 complexes, which translocate to the nucleus to bind promoters containing the IFN-stimulated response element (ISRE) consensus sequence (fig. 1). A large number of anti-viral genes are regulated through ISREs, such as those encoding IRF-7, protein kinase R (PKR), myxovirus resistance [28], APOBEC3G [29] and many others. IRF-7 is required for the transcription of all IFN- $\alpha$ subsets (IFN- $\alpha 1-12$ ) except IFN- $\alpha 4$ and therefore plays a key role in amplifying the response [30].

Below we discuss examples of three main mechanisms by which viruses block or dampen type I IFN induction or signalling pathways: direct proteolysis of components of the type I IFN system, recruitment of UPS and sequestration of components of the IFN response pathway.

\section{Direct Proteolysis of Components of the IFN System}

To facilitate replication to high titres, viruses have evolved relatively small genomes with maximised coding capacity. Diverse strategies have evolved to increase the amount of functions encoded by such small genomes, both at the transcriptional and translational level. Perhaps the most effective way to increase the protein output from small genomes is exemplified by many of the RNA viruses whose entire viral proteome is translated from a single or from two open reading frames and cleaved to the mature functional proteins by a combination of cellular and viral proteases. Typically, non-structural proteins from such viruses are multifunctional and the viral proteases, which process these large polyproteins, often target the cellular proteome also as described in more detail below. It is through this activity that some of the RNA viruses inhibit the production of IFNs during infection.

A common theme in picornavirus infections for example is the cleavage of cellular proteins by viral proteases in order to create a cellular milieu conducive to viral replication. The IFN pathway was recently shown to be a direct target of protease activity in poliovirus-infected cells [31]. That study showed that the p65 subunit of NF$\kappa \mathrm{B}$ is cleaved and inactivated by the viral $3 \mathrm{C}$ protease. This cleavage occurs in the transactivation domain of p65 and thus the truncated protein cannot form an active transcription factor with the $\mathrm{p} 50$ subunit. As NF- $\kappa \mathrm{B}$ p65/ p50 heterodimers are required for early type I IFN transcription, this is an effective strategy to inhibit the re- sponse. However, poliovirus and some other picornaviruses also induce a general inhibition of host cell gene expression so the production of IFNs and other signalling molecules may also be inhibited by this less specific mechanism. In the case of poliovirus, this host cell shut off is brought about by cleavage of the translation initiation factor eIF4G, inhibiting translation [32], and possibly augmented by cleavage of the TATA-box-binding protein, inhibiting transcription [33], by viral proteins $2 \mathrm{~A}^{\text {pro }}$ and $3 C^{\text {pro }}$ respectively.

Another small RNA viral protease with a well-documented role as a type I IFN antagonist is the NS3/4A protease of hepatitis $\mathrm{C}$ virus (HCV). As with poliovirus $3 \mathrm{C}^{\text {pro }}$, the primary role of this protein is the cleavage of the viral polyprotein to release the mature non-structural proteins, but it also applies its proteolytic activity to the cellular proteins TRIF [34] and MAVS [15, 35]. These important players in the host response are cleaved and inactivated in HCV-infected cells and thus the virus interferes with both the TLR3 and the RIG-I/MDA5 branches of the viral recognition and response apparatus. Similarly to the NS3/4A protease of $\mathrm{HCV}$, hepatitis A virus, a hepatotropic picornavirus, suppresses type I IFN production by targeting the $3 \mathrm{ABC}$ protein precursor to MAVS for proteolysis by the $3 \mathrm{C}$ protease [36].

\section{Recruitment of the UPS}

The UPS is the major system for degradation of cellular proteins. Most cellular protein turnover is achieved through ubiquitin (Ub) tagging of proteins and their subsequent degradation by the proteasome, a multicatalytic protease complex. Proteins to be degraded are covalently conjugated to polymeric chains of Ub by Ub ligase complexes. Polyubiquitin chains of 4, 5 or more units of $\mathrm{Ub}$ are recognised by the proteasome as substrates and are then unfolded and degraded. Because of its central role in the turnover of cellular proteins, activities of the UPS are important for many cellular functions including cell cycle regulation, control of apoptosis and immune surveillance [for recent reviews, see 37-39]. It follows also that some viruses divert the UPS to the specific degradation of proteins of the type I IFN response system to achieve a more favourable environment for viral replication.

For example, a number of viral proteins interfere with type I IFN responses by targeting IRF-3 for degradation by the UPS. Infected cell protein 0 of bovine herpesvirus 1 [40], non-structural protein 1 of rotavirus [41] and the $\mathrm{N}$ proteases of classical swine fever virus [42] and bovine 
viral diarrhea virus [43] all appear to induce proteasomal degradation of IRF-3, such that the transcription of the early IFN genes cannot occur in infected cells. In each of these studies, it was found that expression of the viral protein alone, in the absence of other viral gene products, was sufficient to induce degradation of IRF-3 and that this activity was sensitive to inhibitors of the proteasome. Furthermore, naturally occurring or laboratory-constructed viruses lacking this activity were less cytopathogenic than the corresponding wild-type viruses [40-43]. However, it is not yet known whether these proteins themselves contain Ub ligase activity or whether they redirect cellular ligase complexes to IRF-3.

In another example of viral subversion of the UPS for degradation of proteins of the type I IFN system, the V proteins from the paramyxoviruses, simian virus 5 [44], human parainfluenza virus 2 [45] and mumps virus [46] were described to induce the proteasomal degradation of various STAT proteins, thereby inhibiting the activation of IFN-stimulated gene transcription in the presence of IFN signalling. In these cases, the ubiquitination of the STAT proteins is mediated by the assembly of a multimeric complex including members of the cellular Skp/ Cullin/F-box Ub ligase complex (SCF), the target STAT proteins and, as a scaffold for the assembly of this complex, multimers of the viral V protein $[47,48]$. The viral proteins contain a cysteine-rich zinc-binding C-terminal domain, which is essential for this activity. Because the activation of transcription of ISRE-containing genes by type I IFNs requires heterodimers of STAT1 and 2, the different paramyxoviruses achieve inhibition of this pathway by targeting either STAT1 (simian virus 5 [44] and mumps virus [46]) or STAT2 (human parainfluenza virus 2 [45]). Mumps virus also targets STAT3 for degradation in a similar manner and thus inhibits IL-6 signalling [46].

The literature on retroviruses and their potential to interfere with type I IFN responses is more limited. It is known that human immunodeficiency virus type 1 (HIV1) is sensitive to the effect of type I IFNs and that this is, at least in part, mediated by an upregulation of the expression of the anti-retroviral protein APOBEC3G [29]. This protein is a cytidine deaminase, which is packaged into viral particles and in virus-infected cells induces debilitating mutations in nascent viral DNA during firststrand synthesis. The HIV-1 accessory protein Vif is a viral antagonist of this potent antiviral mechanism [49]. In a manner similar to that of the paramyxovirus $\mathrm{V}$ protein, Vif promotes assembly of an SCF-like complex, which in turn promotes polyubiquitination and protea- somal degradation of APOBEC3G. The potency of this immune escape mechanism is illustrated by the observation that the Vif-SCF interaction is a major determinant of species specificity in that viruses which lack this interaction have attenuated phenotypes [for review, see 50].

\section{Sequestration of Components of the IFN Response Pathway}

A very common mechanism for blocking the production or action of type I IFNs used by viruses of many diverse families is the binding and sequestering of key players in these pathways into inactive or unrecognisable states. The double-stranded RNA (dsRNA) molecules or other viral RNA replication intermediates that are formed during many viral infections are clearly potent inducers of type I IFN production, whether through the TLR3 pathway or via recognition by the cytosolic receptors RIG-I/MDA5. Two well-characterised proteins encoded by viruses from very different families, poxvirus E3L and influenza A virus NS1, were shown to block activation of these receptors and consequently to inhibit the IFN response to infection with these viruses [51, 52]. Both proteins have been known for some time to contain dsRNAbinding domains $[53,54]$ and mutation of these domains destroy the IFN antagonistic effect $[52,55]$. One of the major effectors of the type I IFN-induced antiviral state is PKR, which is also activated by dsRNA molecules. PKR acts to phosphorylate the translation initiation factor, eIF2 and thus blocks cellular and viral protein production in infected cells. Sequestration of dsRNA molecules by the NS1 protein thus also blocks activation of this antiviral gene product [56]. Despite the observation that poxvirus E3L can inhibit PKR activation [54], this virus also encodes another PKR antagonist, K3L [57], highlighting the importance of PKR in poxvirus infections.

Some viruses encode analogues of cellular proteins, which can block the activation or action of the type I IFN pathway by sequestration of proteins normally bound by the cellular analogue. African swine fever virus encodes a protein, A238L, which acts to block IFN synthesis in infected cells in an original manner [58]. The protein is an analogue of Iк $B$, which can bind to the $\mathrm{p} 65$ monomer of NF- $\kappa \mathrm{B}$, blocking its entry into the nucleus and the activation of IFN transcription. African swine fever virus infection induces the ubiquitination and degradation of I $\mathrm{B}$, but the $\mathrm{A} 238 \mathrm{~L}$ gene product replaces IкB in the complex and maintains p65 in the cytoplasm, blocking NF$\kappa \mathrm{B}$-dependent transcription. 
Examples of viral proteins that block the activity of components of the IFN pathway by binding and sequestering them are not restricted to the type I IFN induction pathway, but can also affect signalling. For example, the human papilloma virus-18 E6 protein binds to the IFNAR-associated kinase Tyk 2 and blocks its ability to activate the STAT1/2 heterodimers upon IFN receptor engagement [59]. There is even a viral antagonist that acts as soluble IFN receptor analogue in the extracellular environment [60]. This viral IFNAR analogue, encoded by the $\mathrm{B} 18 \mathrm{R}$ gene of vaccinia virus, binds to IFN- $\alpha$ at high affinity and blocks its interaction with host IFNAR molecules to facilitate viral replication.

\section{Concluding Remarks}

The co-evolution of different viruses and their hosts has led to the development of a plethora of viral strategies for subversion of the immune response. The type I IFN system is a prime example of this. It can be blocked or repressed at almost every step by a wide range of viruses and yet remains an important factor in viral resistance. Different viruses clearly have different sensitivities to the anti-viral effects of the system as illustrated by their mode of inhibition. Viruses that are highly sensitive to type I IFNs tend to block IFN induction, while others encode antagonists only to IFN signalling or even to individual IFN-induced effector proteins. It is also evident that some viruses encode more than one antagonist of the system, possibly suggesting that different actions are required at different stages of the viral life cycles. Many of the known viral type I IFN antagonists were discovered in recent years and it is reasonable to assume that there are many more to be discovered.

\section{Acknowledgements}

This work was supported by grants from the Swedish Research Council to G.M.M. (project No. K2008-56X-20666-01-3) and to G.K.H. (project No. K2007-57X-20352-01-3).

\section{References}

$\checkmark 1$ Honda K, Yanai H, Negishi H, Asagiri M, Sato M, Mizutani T, Shimada N, Ohba Y, Takaoka A, Yoshida N, Taniguchi T: IRF-7 is the master regulator of type-I interferon-dependent immune responses. Nature 2005; 434:772-777.

-2 Muller U, Steinhoff U, Reis LF, Hemmi S, Pavlovic J, Zinkernagel RM, Aguet M: Functional role of type I and type II interferons in antiviral defense. Science 1994;264:19181921.

-3 Sato M, Suemori H, Hata N, Asagiri M, Ogasawara K, Nakao K, Nakaya T, Katsuki M, Noguchi S, Tanaka N, Taniguchi T: Distinct and essential roles of transcription factors IRF-3 and IRF-7 in response to viruses for IFN- $\alpha / \beta$ gene induction. Immunity $2000 ; 13$ : 539-548.

4 Dupuis S, Jouanguy E, Al-Hajjar S, Fieschi C, Al-Mohsen IZ, Al-Jumaah S, Yang K, Chapgier A, Eidenschenk C, Eid P, Al Ghonaium A, Tufenkeji H, Frayha H, Al-Gazlan S, AlRayes H, Schreiber RD, Gresser I, Casanova JL: Impaired response to interferon- $\alpha / \beta$ and lethal viral disease in human STAT1 deficiency. Nat Genet 2003;33:388-391.

5 Fazakerley JK, Boyd A, Mikkola ML, Kaariainen L: A single amino acid change in the nuclear localization sequence of the nsP2 protein affects the neurovirulence of Semliki Forest virus. J Virol 2002;76:392-396.
-6 Wang F, Ma Y, Barrett JW, Gao X, Loh J, Barton E, Virgin HW, McFadden G: Disruption of Erk-dependent type I interferon induction breaks the myxoma virus species barrier. Nat Immunol 2004;5:1266-1274.

7 Haller O, Kochs G, Weber F: The interferon response circuit: induction and suppression by pathogenic viruses. Virology 2006;344: $119-130$

8 Hiscott J, Nguyen TL, Arguello M, Nakhaei P, Paz S: Manipulation of the nuclear factor$\kappa \mathrm{B}$ pathway and the innate immune response by viruses. Oncogene 2006;25:6844-6867.

$\checkmark 9$ Randall RE, Goodbourn S: Interferons and viruses: an interplay between induction, signalling, antiviral responses and virus countermeasures. J Gen Virol 2008;89:1-47.

$\checkmark 10$ Breakwell L, Dosenovic P, Karlsson Hedestam GB, D’Amato M, Liljestrom P, Fazakerley J, McInerney GM: Semliki Forest virus nonstructural protein 2 is involved in suppression of the type I interferon response. J Virol 2007;81:8677-8684.

11 Andrejeva J, Childs KS, Young DF, Carlos TS, Stock N, Goodbourn S, Randall RE: The $\mathrm{V}$ proteins of paramyxoviruses bind the IFN-inducible RNA helicase, MDA-5, and inhibit its activation of the IFN- $\beta$ promoter. Proc Natl Acad Sci USA 2004;101:1726417269.
12 Yoneyama M, Kikuchi M, Natsukawa T, Shinobu N, Imaizumi T, Miyagishi M, Taira K, Akira S, Fujita T: The RNA helicase RIG-I has an essential function in double-stranded RNA-induced innate antiviral responses. Nat Immunol 2004;5:730-737.

13 Kato H, Takeuchi O, Sato S, Yoneyama M, Yamamoto M, Matsui K, Uematsu S, Jung A, Kawai T, Ishii KJ, Yamaguchi O, Otsu K, Tsujimura T, Koh CS, Reis e Sousa C, Matsuura Y, Fujita T, Akira S: Differential roles of MDA5 and RIG-I helicases in the recognition of RNA viruses. Nature 2006;441:101105.

14 Kawai T, Takahashi K, Sato S, Coban C, Kumar H, Kato H, Ishii KJ, Takeuchi O, Akira S: IPS-1, an adaptor triggering RIG-I- and Mda5-mediated type I interferon induction. Nat Immunol 2005;6:981-988.

- 15 Meylan E, Curran J, Hofmann K, Moradpour D, Binder M, Bartenschlager R, Tschopp $\mathrm{J}$ : Cardif is an adaptor protein in the RIG-I antiviral pathway and is targeted by hepatitis C virus. Nature 2005;437:1167-1172.

16 Seth RB, Sun L, Ea CK, Chen ZJ: Identification and characterization of MAVS, a mitochondrial antiviral signaling protein that activates NF- $\kappa \mathrm{B}$ and IRF 3. Cell 2005;122: 669-682.

-17 Xu LG, Wang YY, Han KJ, Li LY, Zhai Z, Shu $\mathrm{HB}$ : VISA is an adapter protein required for virus-triggered IFN- $\beta$ signaling. Mol Cell 2005; 19:727-740. 
$\checkmark 18$ Fitzgerald KA, McWhirter SM, Faia KL, Rowe DC, Latz E, Golenbock DT, Coyle AJ, Liao SM, Maniatis T: IKK $\varepsilon$ and TBK1 are essential components of the IRF3 signaling pathway. Nat Immunol 2003;4:491-496.

19 Chen ZJ: Ubiquitin signalling in the NF- $к B$ pathway. Nat Cell Biol 2005;7:758-765.

20 Maniatis T, Falvo JV, Kim TH, Kim TK, Lin $\mathrm{CH}$, Parekh BS, Wathelet MG: Structure and function of the interferon- $\beta$ enhanceosome. Cold Spring Harb Symp Quant Biol 1998;63: 609-620.

21 Kato H, Sato S, Yoneyama M, Yamamoto M, Uematsu S, Matsui K, Tsujimura T, Takeda K, Fujita T, Takeuchi O, Akira S: Cell typespecific involvement of RIG-I in antiviral response. Immunity 2005;23:19-28.

-22 Alexopoulou L, Holt AC, Medzhitov R, Flavell RA: Recognition of double-stranded RNA and activation of NF- $\kappa$ B by Toll-like receptor 3. Nature 2001;413:732-738.

23 Diebold SS, Kaisho T, Hemmi H, Akira S, Reis ESC: Innate antiviral responses by means of TLR7-mediated recognition of single-stranded RNA. Science 2004;303:15291531.

-24 Heil F, Hemmi H, Hochrein H, Ampenberger F, Kirschning C, Akira S, Lipford G, Wagner H, Bauer S: Species-specific recognition of single-stranded RNA via toll-like receptor 7 and 8. Science 2004;303:1526-1529.

25 Lund J, Sato A, Akira S, Medzhitov R, Iwasaki A: Toll-like receptor 9-mediated recognition of Herpes simplex virus-2 by plasmacytoid dendritic cells. J Exp Med 2003;198: 513-520.

26 Colonna M, Krug A, Cella M: Interferonproducing cells: on the front line in immune responses against pathogens. Curr Opin Immunol 2002;14:373-379.

27 Kawai T, Akira S: Innate immune recognition of viral infection. Nat Immunol 2006;7: 131-137.

28 Stark GR, Kerr IM, Williams BR, Silverman RH, Schreiber RD: How cells respond to interferons. Annu Rev Biochem 1998;67:227264.

-29 Peng G, Lei KJ, Jin W, Greenwell-Wild T, Wahl SM: Induction of APOBEC3 family proteins, a defensive maneuver underlying interferon-induced anti-HIV-1 activity. Exp Med 2006;203:41-46.

-30 Marie I, Durbin JE, Levy DE: Differential viral induction of distinct interferon-alpha genes by positive feedback through interferon regulatory factor-7. Embo J 1998;17: 6660-6669.

-31 Neznanov N, Chumakov KM, Neznanova L, Almasan A, Banerjee AK, Gudkov AV: Proteolytic cleavage of the p65-RelA subunit of NF- $\mathrm{BB}$ during poliovirus infection. J Biol Chem 2005;280:24153-24158.

- 32 Krausslich HG, Nicklin MJ, Toyoda H, Etchison $\mathrm{D}$, Wimmer E: Poliovirus proteinase $2 \mathrm{~A}$ induces cleavage of eucaryotic initiation factor $4 \mathrm{~F}$ polypeptide p220. J Virol 1987;61: 2711-2718.
33 Clark ME, Lieberman PM, Berk AJ, Dasgupta A: Direct cleavage of human TATA-binding protein by poliovirus protease $3 \mathrm{C}$ in vivo and in vitro. Mol Cell Biol 1993;13:12321237.

34 Li K, Foy E, Ferreon JC, Nakamura M, Ferreon AC, Ikeda M, Ray SC, Gale M, Jr., Lemon SM: Immune evasion by hepatitis $C$ virus NS3/4A protease-mediated cleavage of the Toll-like receptor 3 adaptor protein TRIF. Proc Natl Acad Sci USA 2005; 102:29922997.

35 Lin R, Lacoste J, Nakhaei P, Sun Q, Yang L, Paz S, Wilkinson P, Julkunen I, Vitour D, Meurs E, Hiscott J: Dissociation of a MAVS/ IPS-1/VISA/Cardif-IKKepsilon molecular complex from the mitochondrial outer membrane by hepatitis C virus NS3-4A proteolytic cleavage. J Virol 2006;80:6072-6083.

-36 Yang Y, Liang Y, Qu L, Chen Z, Yi M, Li K, Lemon SM: Disruption of innate immunity due to mitochondrial targeting of a picornaviral protease precursor. Proc Natl Acad Sci USA 2007;104:7253-7258.

37 Bhoj VG, Chen ZJ: Ubiquitylation in innate and adaptive immunity. Nature 2009;458: 430-437.

38 Hoeller D, Dikic I: Targeting the ubiquitin system in cancer therapy. Nature 2009;458: 438-444.

-39 Yang Y, Yu X: Regulation of apoptosis: the ubiquitous way. FASEB J 2003;17:790-799.

40 Saira K, Zhou Y, Jones C: The infected cell protein 0 encoded by bovine herpesvirus 1 (bICP0) induces degradation of interferon response factor 3 and, consequently, inhibits $\beta$ interferon promoter activity. J Virol 2007; 81:3077-3086.

41 Barro M, Patton JT: Rotavirus nonstructural protein 1 subverts innate immune response by inducing degradation of IFN regulatory factor 3. Proc Natl Acad Sci USA 2005; 102: 4114-4119.

-42 Seago J, Hilton L, Reid E, Doceul V, Jeyatheesan J, Moganeradj K, McCauley J, Charleston B, Goodbourn S: The N ${ }^{\text {pro }}$ product of classical swine fever virus and bovine viral diarrhea virus uses a conserved mechanism to target interferon regulatory factor-3. J Gen Virol 2007;88:3002-3006.

43 Hilton L, Moganeradj K, Zhang G, Chen YH, Randall RE, McCauley JW, Goodbourn S: The $\mathrm{N}^{\text {Pro }}$ product of bovine viral diarrhea virus inhibits DNA binding by interferon regulatory factor 3 and targets it for proteasomal degradation. J Virol 2006;80:1172311732.

44 Didcock L, Young DF, Goodbourn S, Randall RE: The $V$ protein of simian virus 5 inhibits interferon signalling by targeting STAT1 for proteasome-mediated degradation. J Virol 1999;73:9928-9933.
45 Parisien JP, Lau JF, Rodriguez JJ, Sullivan BM, Moscona A, Parks GD, Lamb RA, Horvath $C M$ : The $V$ protein of human parainfluenza virus 2 antagonizes type I interferon responses by destabilizing signal transducer and activator of transcription 2. Virology 2001;283:230-239.

46 Ulane CM, Rodriguez JJ, Parisien JP, Horvath CM: STAT3 ubiquitylation and degradation by mumps virus suppress cytokine and oncogene signaling. J Virol 2003;77: 6385-6393.

-47 Andrejeva J, Poole E, Young DF, Goodbourn S, Randall RE: The p127 subunit (DDB1) of the UV-DNA damage repair binding protein is essential for the targeted degradation of STAT1 by the $\mathrm{V}$ protein of the paramyxovirus simian virus 5. J Virol 2002;76:1137911386.

48 Ulane CM, Kentsis A, Cruz CD, Parisien JP, Schneider KL, Horvath CM: Composition and assembly of STAT-targeting ubiquitin ligase complexes: paramyxovirus $\mathrm{V}$ protein carboxyl terminus is an oligomerization domain. J Virol 2005;79:10180-10189.

49 Yu X, Yu Y, Liu B, Luo K, Kong W, Mao P, Yu XF: Induction of APOBEC3G ubiquitination and degradation by an HIV-1 Vif-Cul5-SCF complex. Science 2003;302:1056-1060.

50 Holmes RK, Malim MH, Bishop KN: APOBEC-mediated viral restriction: not simply editing? Trends Biochem Sci 2007;32:118128.

51 Chang HW, Watson JC, Jacobs BL: The E3L gene of vaccinia virus encodes an inhibitor of the interferon-induced, double-stranded RNA-dependent protein kinase. Proc Natl Acad Sci USA 1992;89:4825-4829.

52 Wang X, Li M, Zheng H, Muster T, Palese P, Beg AA, Garcia-Sastre A: Influenza A virus NS1 protein prevents activation of NF- $\mathrm{B}$ and induction of $\alpha / \beta$ interferon. J Virol 2000;74:11566-11573.

53 Hatada E, Fukuda R: Binding of influenza A virus NS1 protein to dsRNA in vitro. J Gen Virol 1992;73:3325-3329.

54 Watson JC, Chang HW, Jacobs BL: Characterization of a vaccinia virus-encoded double-stranded RNA-binding protein that may be involved in inhibition of the doublestranded RNA-dependent protein kinase. Virology 1991;185:206-216.

55 Chang HW, Uribe LH, Jacobs BL: Rescue of vaccinia virus lacking the E3L gene by mutants of E3L. J Virol 1995;69:6605-6608.

56 Bergmann M, Garcia-Sastre A, Carnero E, Pehamberger H, Wolff K, Palese P, Muster T: Influenza virus NS1 protein counteracts PKR-mediated inhibition of replication. J Virol 2000;74:6203-6206.

57 Davies MV, Elroy-Stein O, Jagus R, Moss B, Kaufman RJ: The vaccinia virus K3L gene product potentiates translation by inhibiting double-stranded-RNA-activated protein kinase and phosphorylation of the alpha subunit of eukaryotic initiation factor 2. J Virol 1992;66:1943-1950. 
58 Tait SW, Reid EB, Greaves DR, Wileman TE, Powell PP: Mechanism of inactivation of NF$\kappa \mathrm{B}$ by a viral homologue of I $\mathrm{B} \alpha$. Signal-induced release of $\mathrm{I} \kappa \mathrm{B} \alpha$ results in binding of the viral homologue to NF- $\mathrm{B}$. J Biol Chem 2000;275:34656-34664.

59 Li S, Labrecque S, Gauzzi MC, Cuddihy AR, Wong AH, Pellegrini S, Matlashewski GJ, Koromilas AE: The human papilloma virus (HPV)-18 E6 oncoprotein physically associates with Tyk 2 and impairs Jak-STAT activation by interferon-alpha. Oncogene 1999;18: 5727-5737.

60 Symons JA, Alcami A, Smith GL: Vaccinia virus encodes a soluble type I interferon receptor of novel structure and broad species specificity. Cell 1995;81:551-560.

61 Gack MU, Albrecht RA, Urano T, Inn KS, Huang IC, Carnero E, Farzan M, Inoue S, Jung JU, Garcia-Sastre A: Influenza A virus NS1 targets the ubiquitin ligase TRIM25 to evade recognition by the host viral RNA sensor RIG-I. Cell Host Microbe 2009;5:439449.
62 Elliott J, Lynch OT, Suessmuth Y, Qian P, Boyd CR, Burrows JF, Buick R, Stevenson NJ Touzelet O, Gadina M, Power UF, Johnston JA: Respiratory syncytial virus NS1 protein degrades STAT2 by using the Elongin-Cullin E3 ligase. J Virol 2007;81:3428-3436.

63 Paulus C, Krauss S, Nevels M: A human cytomegalovirus antagonist of type I IFN-dependent signal transducer and activator of transcription signaling. Proc Natl Acad Sci USA 2006;103:3840-3845.

64 Lin W, Kim SS, Yeung E, Kamegaya Y, Blackard JT, Kim KA, Holtzman MJ, Chung RT: Hepatitis $\mathrm{C}$ virus core protein blocks interferon signaling by interaction with the STAT1 SH2 domain. J Virol 2006;80:92269235.
65 Wu M, Xu Y, Lin S, Zhang X, Xiang L, Yuan $\mathrm{Z}$ : Hepatitis B virus polymerase inhibits the interferon-inducible MyD88 promoter by blocking nuclear translocation of Stat1. J Gen Virol 2007;88:3260-3269.

-66 Rodriguez JJ, Wang LF, Horvath CM: Hendra virus $\mathrm{V}$ protein inhibits interferon signaling by preventing STAT1 and STAT2 nuclear accumulation. J Virol 2003;77: 11842-11845.

-67 Nanda SK, Baron MD: Rinderpest virus blocks type I and type II interferon action: role of structural and nonstructural proteins. J Virol 2006;80:7555-7568.

-68 Mann BA, Huang JH, Li P, Chang HC, Slee RB, O’Sullivan A, Anita M, Yeh N, Klemsz MJ, Brutkiewicz RR, Blum JS, Kaplan MH: Vaccinia virus blocks Stat1-dependent and Stat1-independent gene expression induced by type I and type II interferons. J Interferon Cytokine Res 2008;28:367-380. 